\title{
SUSTAINABLE CONSUMPTION THROUGH INNOVATIVE USE: MARKE EIGENBAU IN THE FORMER EAST GERMANY
}

\author{
Marco Wolf, University of Southern Mississippi, USA \\ Pia A. Albinsson, Appalachian State University, USA \\ Dennis A. Kopf, University of Wisconsin - Whitewater, USA
}

\begin{abstract}
The problems of over-consumption, environmental degradation, and depletion of resources have initiated research in the area of sustainable consumption. The basic premise of sustainable consumption seeks to address the negative impacts of dominating consumption patterns in affluent countries and their need to substantially reduce their consumption to achieve sustainability (Schrader and Thorgersen, 2011). With this macro-level problem in mind, researchers have focused on the roles and responsibilities of both companies and consumers. On the consumer side, two perspectives prevail. First, consumers can choose environmentally friendly products and 'green' consumption (Moisander, 2007). The second perspective is that consumers can consume less or even choose not to consume. These perspectives entail a moral obligation and personal commitment to downscale consumption to reduce or eliminate negative externalities on people and the environment (Press and Arnould, 2009). Consumer-centric and company-centric viewpoints are both necessary. With this research, we take a consumer-centric approach. More specifically, we are interested in consumption that is less wasteful. We look back in time to the days of the former East Germany and examine behavior commonly known as Marke Eigenbau (loosely translated as 'Do-It-Yourself Brand'). Recent discussions have highlighted Marke Eigenbau as a movement against mass production, however, research has not realized Marke Eigenbau to its fullest potential, and thus we analyze Marke Eigenbau in the light of sustainable consumption and the lessons that can be learned from a society with limited resources.
\end{abstract}

In this exploratory study, we use an interpretive methodological approach (Lincoln and Guba, 1985), which allows us to investigate consumers' use-innovative approaches to produce their own goods and extend product lifecycles in DIY efforts. Data was collected in areas of the former East Germany. Twelve informal, unstructured interviews assisted us in developing our final interview guidelines. These guidelines were then used for twenty formal interviews with informants who had experiences from living in a planned economy, which shaped their current consumption behaviors. Interviews were conducted in German, digitally recorded and transcribed in German (and later translated into English). Informants were interviewed in their homes or at local coffee shops. Informants varied in ages from 27- 77 years old and interview times ranged between one and two hours.

This study identifies three preliminary themes that illustrate how consumers sought meaning to their DIY activities; (1) Scarcity - the driver for innovation: To fill the void of unavailable but desired consumer goods, East Germans became efficient in collecting and reusing products in very innovative ways. Our informants stated that rarely were things thrown away even when the product didn't serve its intended purpose. Eventually, out served goods were integrated with innovativeness, frugality, and ingenuity became national values and the productive ownership and creation of things was elevated to a virtue. Scarcity was seen as a challenge to the industriousness of a culture that prided itself on its engineering and scientific ability. (2) Self-expression through Marke Eigenbau: Marketing was limited in the command economy. People could only buy what the state deemed important. Variety was sacrificed for the sake of efficiency. For instance, there was mainly one type of car, the Trabant. But, this didn't stop East Germans from modifying their Trabants to fit their own sense of style and uniqueness. The need for uniqueness and variety trumped the need for efficiency so, again, East Germans turned to DIY activities. (3) Meaning and purpose for old material possessions: Our data analysis illustrate that DIY behavior infused meaning into objects allowing each object to represent a story of its creation, use, and in many cases the maintenance and improvement of the object over time. This is partially a result of the immense personal effort and innovativeness that goes into not only purchasing, but also maintaining goods. This reflects a different culture of ownership of material possessions than what we see in the West. The labor spent maintaining, improving, and sometimes stylizing vehicles made the ownership more personal.

In conclusion, in terms of sustainability, Marke Eigenbau, as practiced in East Germany, is somewhat different than modern DIY. Products, for example, were usually assembled from an assortment of whatever materials the East Germans had available and often involved a painstaking process to find the materials necessary to even begin the project. This inadequate supply and the nonexistence of home improvement stores make Marke Eigenbau a subject of unique consumer behaviors. We discuss how this research can be applied in a world where raw materials are becoming scarcer and in a world where sustainability and the preservation of the environment are becoming increasingly important.

References available upon request.

Proceedings of AMS' World Marketing Congress Cultural Perspectives in Marketing (C 2012 